\title{
Comparison between Platelet Rich Plasma and Corticosteroid Injection in Treatment of Plantar Fasciitis: A Systematic Review
}

\author{
Amr Farouk Abdel Rahman ${ }^{1 *}$, Ossama Elshazly ${ }^{1}$, Amro Shouman ${ }^{1}$ and Mohammed Abd Elghany ${ }^{2}$ \\ ${ }^{1}$ Department of Orthopedic Surgery, Ain Shams University, Egypt \\ ${ }^{2}$ Department of Orthopedic Surgery, Badr Hospital, Egypt
}

Submission: February 24, 2018; Published: March 26, 2018

*Corresponding author: Amr Farouk Abdel Rahman, Lecturer of Orthopedic surgery, Ain Shams University, Tel: (202)-01007090067; Email: amrbekfarouk@hotmail.com

\begin{abstract}
Background: with the increasing interest in platelet-rich plasma (PRP) injection as a treatment for chronic plantar fasciitis (pf), we intended to compare the clinical difference between the use of PRP and cortisone injection in the treatment of chronic pf.

Methods: Four electronic database were searched (PubMed ,Medline ,google scholar, Cochrane) using the following keywords (plantar fasciitis, corticosteroid injection in plantar fasciitis, PRP in plantar fasciitis ) with inclusion criteria (English literature only, human study only and randomized control trial \& case series related to treatment of plantar fasciitis with PRP and corticosteroid.) and exclusion criteria (duplicated articles by the same authors unless with longer follow-up studies and non-English studies). All patients in these studies underwent injection after at least 3 months of complain and failure of conservative treatment. Follow-up duration was (1.5, 3\&6 months) in most of these studies.

Results: our search revealed 8 studies accounting for total of 376 patients (188 patients in PRP group and 188 patients is steroid group) diagnosed as chronic plantar fasciitis included in the final analysis. Their ages ranged from 21 to 85 years old with a mean age 47.13 year for steroid group and 44.95 years for PRP group. Mean VAS (Visual analogue scale) for pain results at baseline and at end of follow-up in steroid group are 7.3 \& 3.01 respectively and in PRP group are 7.3 \& 2 respectively. Mean AOFAS results at baseline and at end of follow-up in steroid group are $52.2 \& 74.69$ respectively and in PRP group are $50.46 \& 59.95$ respectively. (P value $<0.05$ ).
\end{abstract} foot.

Conclusion: PRP injection is better than steroid injection in relieving the pain of planar fasciitis and improvement function of the patient

Keywords: Plantar fasciitis; Corticosteroid injection in plantar fasciitis; PRP in plantar fasciitis

\section{Introduction}

Plantar fasciitis is a disorder that results in pain in the heel and bottom of the foot [1]. Pain is usually most severe with the first steps of the day or following a period of rest [2]. Pain is also frequently brought on by bending the foot and toes up towards the shin and may be worsened by a tight Achilles tendon [3]. The condition typically progresses slowly. In about a third of people both legs are affected [1]. Typically there are no fevers or night sweats.

Risk factors include overuse such as from long periods of standing, an increase in exercise, and obesity [1]. It is also associated with inward rolling of the foot and a lifestyle that involves little exercise. While heel spurs are frequently found it is unclear if they have a role in causing the disease. Plantar fasciitis is a disorder of the insertion site of the ligament on the bone characterized by micro tears, breakdown of collagen, and scarring [1]. As inflammation plays a lesser role, many feel the condition should be renamed plantar fasciosis [4]. The diagnosis is typically based on signs and symptoms with ultrasound sometimes used to help [1]. Other conditions with similar symptoms include osteoarthritis, ankylosing spondylitis, heel pad syndrome, and reactive arthritis [5].

Most cases of plantar fasciitis resolve with time and conservative methods of treatment [6]. Usually for the first few weeks people are advised to rest, change their activities, take pain medications, and stretch. If this is not sufficient physiotherapy, orthotics, splinting, or steroid injections may be options. When plantar fasciitis occurs, the pain is typically sharp [7] and usually unilateral (70\% of cases) [6]. Heel pain worsens by bearing weight on the heel after long periods of rest [8]. Individuals with plantar fasciitis often report their symptoms are most intense during their first steps after getting out of bed or after prolonged periods of sitting [2]. Improvement 
of symptoms is usually seen with continued walking [9]. Rare, but reported symptoms include numbness, tingling, swelling, or radiating pain [10]. Typical signs and symptoms of plantar fascia rupture include a clicking or snapping sound, significant local swelling and acute pain in the sole of the foot [7].

Many modalities are available to treat this condition, of which corticosteroid injection is, perhaps, the most popular. However, recent years have seen an increased interest in the use of plateletrich plasma (PRP) injections in various clinical situations such as plantar fasciitis [3]. Both methods are effective and successful in treating plantar fasciitis. When the potential complication of corticosteroid treatment is taken into consideration, plateletrich plasma (PRP) injection seems to be safer and at least having same effectivity in the treatment of plantar fasciitis [11].

\section{Materials and Methods}

This systematic review is to compare platelet rich plasma and corticosteroid injection in the treatment of plantar fasciitis.

PubMed, Medline, Google-scholar, Cochrane searches were done on the following keywords:

i. Plantar fasciitis,

ii. Corticosteroid injection in plantar fasciitis,

iii. PRP in plantar fasciitis.

Inclusion criteria for the search included:

a. English literature only.

b. Human study only.

c. Randomized control trial \& case series related to treatment of plantar fasciitis with PRP and corticosteroid.

The exclusion criteria for the search included:

i. Duplicated articles by the same authors unless with longer follow-up studies.

ii. Non-English studies.

Articles in this study included up to date management of plantar fasciitis using platelet rich plasma versus corticosteroid.

The search steps are shown in Figure 1.

Injection technique $[8,11]$ : Figure 2

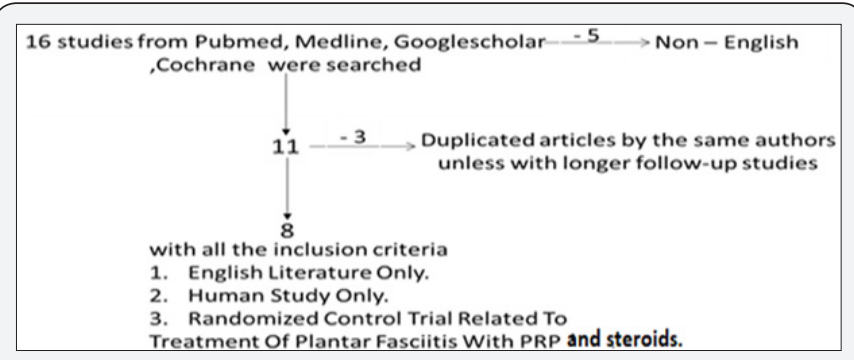

Figure 1: Flowchart showing the search steps.

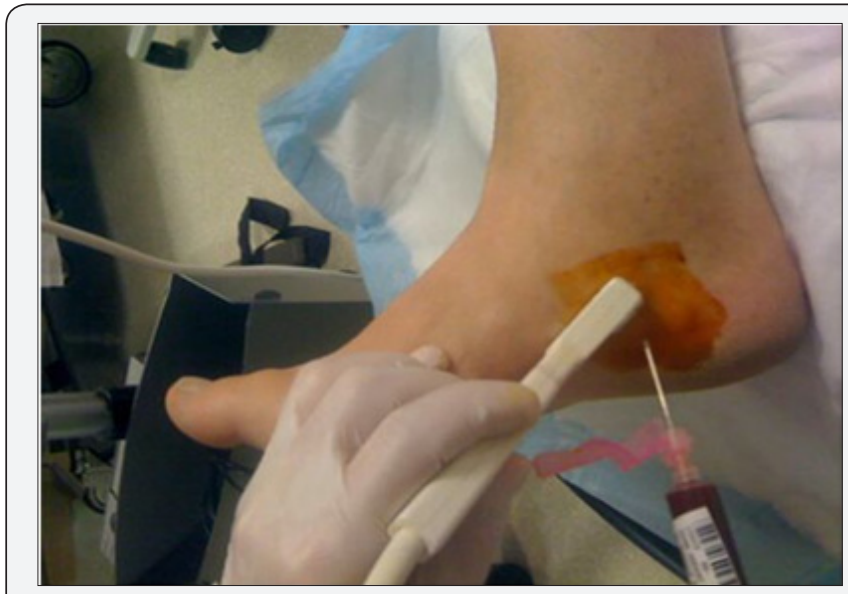

Figure 2 : The injection technique [9].

The procedure was done on out-patient basis under complete aseptic condition

i. Position: the patient lay supine with lower limb externally rotated.

ii. Disinfection: skin dis-infection with betadine.

iii. Anesthesia: Post. tibial nerve block by lidocaine injected finger breadth behind and below medial malleolus and ultrasound guided.

iv. Technique: identification of site of thickest part of plantar fascia by ultrasound

Amount of PRP was injected at sites of maximum tenderness and thickest part of plantar fascia by peppering technique (needle was repeatedly inserted and reinserted in affected area).

And the amount of steroid was injected at site of maximum tenderness.

Post-injection precautions $[11,12]$ :

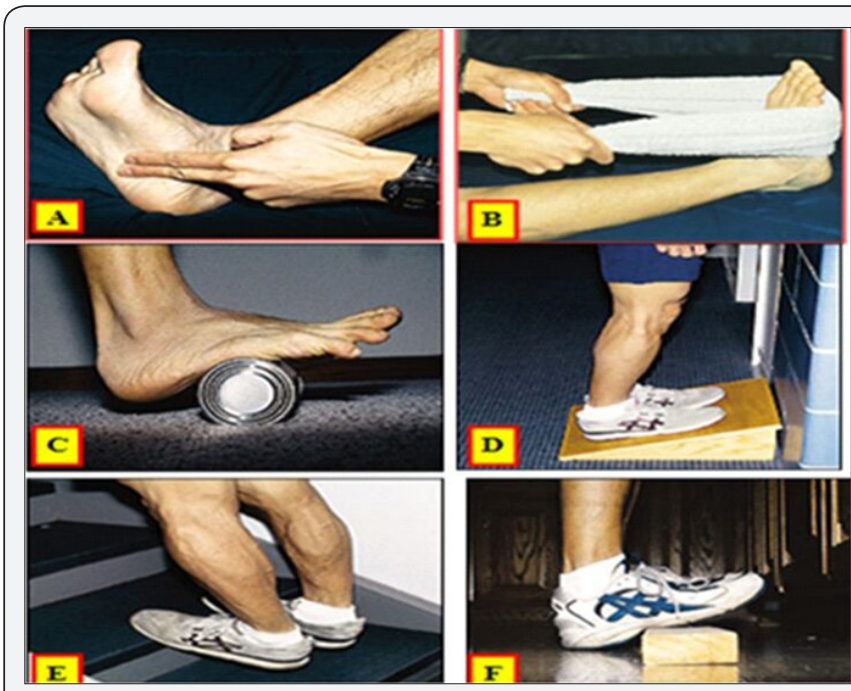

Figure 3 : plantar fascia specific stretch exercises after 4 days and for 4 weeks post injection [18]. 


\section{Orthopedics and Rheumatology Open Access Journal}

a. Acetaminophen (paracetamol) is only allowed as analgesic after procedure.

b. Ice packs, rest and leg elevation for 72 hours.

c. Avoid full weight bearing for 48 hours.

d. Gradual return to activity.

e. Plantar fascia specific stretch exercises after 4 days and for 4 weeks as shown in Figure 3 [13].

Results

Our online search revealed 8 studies from 2012 to 2017 accounting for total of 376 patients (188 patients in PRP group and 188 patients in steroid group )included in the final analysis as following (Ertuğrul Akşahin, et al. ) (Total 60 patients), Mukesh Tiwari, et al. (Total 60 patients), (Vijay D. Shetty M.S, et al.) (Total 60 patients), (Raymond Rocco Monto et al.) (total 40 patients), (Babak Vahdatpour, et al.) (Total 32 patients), \{Kowshik Jain Philip, et al.) (Total 46 patients), (Mohammed A Mortada et al.) (Total 50 patients), (Acosta-Olivo $\mathrm{C}$ et al.) (Total 28 patients), in all studies the patients were divided into 2 groups group a for steroid injection with mean age of 47.13 years and group $b$ for PRP (platelet-rich plasma) with mean age of 44.95 years old. In all studies there was no significant difference between 2 groups regarding demographic data as shown in Table 1.

Table 1: Showing number, Age (mean) \& Sex of each study.

\begin{tabular}{|c|c|c|c|c|c|c|c|c|c|}
\hline \multirow{2}{*}{$\begin{array}{c}\text { Study } \\
\text { Number }\end{array}$} & \multirow{2}{*}{ Year } & \multirow{2}{*}{ Author } & \multicolumn{4}{|c|}{ Number of Patient } & \multicolumn{2}{|c|}{ Age of the patients (mean) } & \multicolumn{2}{c|}{ Sex } \\
\cline { 4 - 11 } & & Total & Steroid & PRP & Steroid & PRP & Steroid & PRP \\
\hline 1 & 2012 & Ertugrul Aksahin, et al. & 60 & 30 & 30 & $45.67 \pm 9.36$ & $46.36 \pm 8.49$ & F:M 18:12 & F:M 17:13 \\
\hline 2 & 2013 & Mukesh Tiwari, et al. & 60 & 30 & 30 & \multicolumn{2}{|c|}{ Not Recorded } & \multicolumn{2}{|c|}{ Not Recorded } \\
\hline 3 & 2013 & Vijay D Shetty M. S, et al. & 60 & 30 & 30 & $39.2 \pm 9.35$ & $34.0 \pm 9.15$ & $17: 13$ & $19: 11$ \\
\hline 4 & 2014 & Raymond Rocco Monto, et al. & 40 & 20 & 20 & 59 & 51 & $11: 9$ & $12: 8$ \\
\hline 5 & 2015 & Babak Vahdatpour, et al. & 32 & 16 & 16 & $47.12 \pm 10.70$ & $45.44 \pm 7.74$ & 11.5 & $12: 4$ \\
\hline 6 & 2015 & Kowshik Jain Philip, et al. & 46 & 23 & 23 & \multicolumn{2}{|c|}{55.6} & FM 16:30 \\
\hline 7 & 2015 & Mohammed A Mortada et al. & 50 & 25 & 25 & $38.52 \pm 6.2$ & $37.48 \pm 8.75$ & $25: 0$ & $23: 2$ \\
\hline 8 & 2017 & Acosta- Olivo C, et al. & 28 & 14 & 14 & \multicolumn{2}{|c|}{44.8} & \multicolumn{2}{|c|}{ F:M 4:1 } \\
\hline
\end{tabular}

All patients in our study underwent injection by steroid or PRP with different doses after at least 3 months of complain and failure of conservative treatment as shown in Table 2. Their improvement was judged clinically by VAS (visual analogue scale) Figure 4 [14] and AOFAS (American orthopaedic Foot and Ankle Society) as shown in Figure 5. The summation of studies' results is shown in Table 3. The difference between VAS results at baseline and at end of follow-up is shown in Table 4 and Figure 6. The difference between mean AOFAS results at baseline and at end of follow-up is shown in Table 5 and Figure 7. From Tables $4 \& 5$ and Figures $6 \& 7$ we could conclude that there is a high significant difference between PRP and steroid in VAS and AOFAS scales ( $\mathrm{p}$ value $>0.05$ ).

Table 2: Showing that all patients in our study underwent injection by steroid or PRP with different doses after at least 3 months of complain and failure of conservative treatment.

\begin{tabular}{|c|c|c|c|c|c|c|}
\hline \multirow{2}{*}{$\begin{array}{c}\text { Study } \\
\text { Number }\end{array}$} & \multirow{2}{*}{ Year } & \multirow{2}{*}{ Author } & \multirow{2}{*}{$\begin{array}{l}\text { Time to } \\
\text { Injection }\end{array}$} & \multirow[t]{2}{*}{ Follow Up } & \multicolumn{2}{|l|}{ Amount of Injections } \\
\hline & & & & & Steroid & PRP \\
\hline 1 & 2012 & $\begin{array}{l}\text { Ertugrul Aksahin, } \\
\text { et al. }\end{array}$ & 3 Months & $\begin{array}{l}3 \text { Weeks and } 6 \\
\text { Months }\end{array}$ & $\begin{array}{l}2 \mathrm{ml} \text { of } 40 \mathrm{mg} \text { Methylprednisolone with } \\
2 \mathrm{ml} \text { of } 2 \% \text { Prilocaine }\end{array}$ & $\begin{array}{l}3 \mathrm{ml}+2 \mathrm{ml} \text { of } 2 \% \\
\text { Prilocaine }\end{array}$ \\
\hline 2 & 2013 & $\begin{array}{l}\text { Mukesh Tiwari, } \\
\text { et al. }\end{array}$ & 6 Months & $1,3 \& 6$ Months & Methylprednisolone acetate $40 \mathrm{mg} / 1 \mathrm{ml}$ & $5 \mathrm{ml}$ \\
\hline 3 & 2013 & $\begin{array}{l}\text { Vijay D Shetty M. } \\
\text { S, et al. }\end{array}$ & 3 Months & 3 Months & $\begin{array}{l}40 \mathrm{mg} \text { of triamcinolone Acetonide }+3 \mathrm{ml} \\
\text { of } 2 \% \text { lignocaine }\end{array}$ & $3 \mathrm{ml}$ \\
\hline 4 & 2014 & $\begin{array}{l}\text { Raymond Rocco } \\
\text { Monto, et al. }\end{array}$ & 4 Months & $\begin{array}{l}\text { 3,6,12, and } 24 \\
\text { Months }\end{array}$ & 40mg DepoMedrol Cortisone & $3 \mathrm{ml}$ \\
\hline 5 & 2015 & $\begin{array}{c}\text { Babak } \\
\text { Vahdatpour, et al. }\end{array}$ & 3 Months & $1,3 \& 6$ Months & Methylprednisolone $1 \mathrm{ml}+$ Lidocaine $1 \mathrm{ml}$ & $3 \mathrm{ml}$ \\
\hline 6 & 2015 & $\begin{array}{l}\text { Kowshik Jain } \\
\text { Philip, et al. }\end{array}$ & 12 Months & $\begin{array}{l}3,6 \text { and } 12 \\
\text { Months }\end{array}$ & 40mg Kenalog+ Chirocaine & $2.5 \mathrm{ml}$ \\
\hline 7 & 2015 & $\begin{array}{l}\text { Mohammed A } \\
\text { Mortada et al. }\end{array}$ & 3 Months & $1.5 \& 3$ Month & $\begin{array}{l}2 \mathrm{ml} \text { Triamcinolone acetonide }(40 \mathrm{mg} / \\
\mathrm{mL})\end{array}$ & $3 \mathrm{ml}$ \\
\hline 8 & 2017 & $\begin{array}{l}\text { Acosta- Olivo } \mathrm{C}, \\
\text { et al. }\end{array}$ & After 3 Months & $\begin{array}{l}\text { 2-4-8-12-16 } \\
\text { Weeks }\end{array}$ & $8 m g+2 m l$ lidocaine & $3 \mathrm{ml}+2 \mathrm{ml}$ lidocaine \\
\hline
\end{tabular}




\section{Orthopedics and Rheumatology Open Access Journal}

Table 3: Showing the summation of studies' results.

\begin{tabular}{|c|c|c|c|c|c|c|c|c|c|c|}
\hline \multirow{3}{*}{$\begin{array}{l}\text { Study } \\
\text { Number }\end{array}$} & \multirow{3}{*}{ Year } & \multirow{3}{*}{ Author } & \multicolumn{4}{|c|}{ VAS } & \multicolumn{4}{|c|}{ AOFAS } \\
\hline & & & \multicolumn{2}{|c|}{ Steroid } & \multicolumn{2}{|c|}{ PRP } & \multicolumn{2}{|c|}{ Steroid } & \multicolumn{2}{|c|}{ PRP } \\
\hline & & & Pre & Post & Pre & Post & Pre & Post & Pre & Post \\
\hline 1 & 2012 & $\begin{array}{c}\text { Ertugrul } \\
\text { Aksahin, et al. }\end{array}$ & $6.2 \pm 1.61$ & $3.4 \pm 2.32$ & $7.33 \pm 0.62$ & $3.93 \pm 2.02$ & \multicolumn{4}{|c|}{ Not Recorded } \\
\hline 2 & 2013 & $\begin{array}{c}\text { Mukesh } \\
\text { Tiwari, et al. }\end{array}$ & $6.03(0.85)$ & $2.8(0.76)$ & $5.9(0.76)$ & $2.0(0.45)$ & \multicolumn{4}{|c|}{ Not Recorded } \\
\hline 3 & 2013 & $\begin{array}{l}\text { Vijay D } \\
\text { Shetty M. S, } \\
\text { et al. }\end{array}$ & $7.8 \pm 1.126$ & $4.27 \pm 1.413$ & $8.1 \pm 1.322$ & $1.8 \pm 1.126$ & $\begin{array}{l}32.5 \pm \\
7.157\end{array}$ & $\begin{array}{l}70.5 \pm \\
9.187\end{array}$ & $\begin{array}{l}33.9 \pm \\
8.155\end{array}$ & $\begin{array}{c}83.1 \pm \\
10.111\end{array}$ \\
\hline 4 & 2014 & $\begin{array}{l}\text { Raymond } \\
\text { Rocco Monto, } \\
\text { et al. }\end{array}$ & \multicolumn{4}{|c|}{ Not Recorded } & 52 & 56 & 37 & 92 \\
\hline 5 & 2015 & $\begin{array}{c}\text { Babak } \\
\text { Vahdatpour, } \\
\text { et al. }\end{array}$ & $7.12 \pm 1.78$ & $4.8 \pm 2.66$ & $8.50 \pm 0.97$ & $1.50 \pm 1.97$ & \multicolumn{4}{|c|}{ Not Recorded } \\
\hline 6 & 2015 & $\begin{array}{l}\text { Kowshik Jain } \\
\text { Philip, et al. }\end{array}$ & $8.27(1.95)$ & $5.33^{* * *}(3.47)$ & $8.30(0.88)$ & $\begin{array}{c}3.30 \\
* * *(3.69)\end{array}$ & $\begin{array}{c}56.70 \\
(16.29)\end{array}$ & $\begin{array}{c}75.07 \\
* * *(20.13) \\
\end{array}$ & $\begin{array}{c}58.63 \\
(15.81)\end{array}$ & $\begin{array}{c}88.50 \\
* * *(13.42) \\
\end{array}$ \\
\hline 7 & 2015 & $\begin{array}{l}\text { Mohammed } \\
\text { A Mortada } \\
\text { et al. }\end{array}$ & $10(9-10)$ & $0(0-10)$ & $9(8-10)$ & $1(0-9)$ & \multicolumn{4}{|c|}{ Not Recorded } \\
\hline 8 & 2017 & $\begin{array}{c}\text { Acosta- Olivo } \\
\text { C, et al. }\end{array}$ & $5.67 \pm 1.54$ & $0.47( \pm 1.3)$ & $4.53 \pm 1.12$ & $0.33( \pm 0.72)$ & $\begin{array}{c}67.6 \pm \\
10.7\end{array}$ & $97.2 \pm 8.4$ & $72.3 \pm 9.1$ & $96.2 \pm 6.0$ \\
\hline
\end{tabular}

Table 4: Difference between mean VAS results at baseline and at end of follow-up.

\begin{tabular}{|c|c|c|c|}
\hline & Baseline & $\begin{array}{l}\text { Post Injection (end of } \\
\text { follow up) }\end{array}$ & P-Value \\
\hline PRP & 7.38 & 2 & \multirow{2}{*}{$\begin{array}{l}0.05>\text { High } \\
\text { Significant } \\
\text { difference }\end{array}$} \\
\hline Steroid & 7.3 & 3.01 & \\
\hline
\end{tabular}

Table 5: Difference between mean AOFAS results at baseline and at end of follow-up.

\begin{tabular}{|c|c|c|c|}
\hline BRP & 50.46 & 89.95 & P-Value \\
\hline Steroid & 52.2 & 74.69 & $\begin{array}{c}\text { Post Injection (end of } \\
\text { follow up) } \\
\text { Significant } \\
\text { difference }\end{array}$ \\
\hline
\end{tabular}

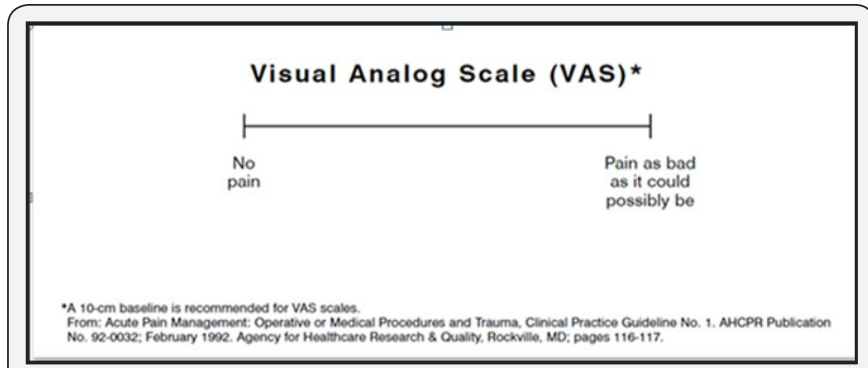

Figure 4 : Figure 4: VAS (Visual analogue scale) [14].

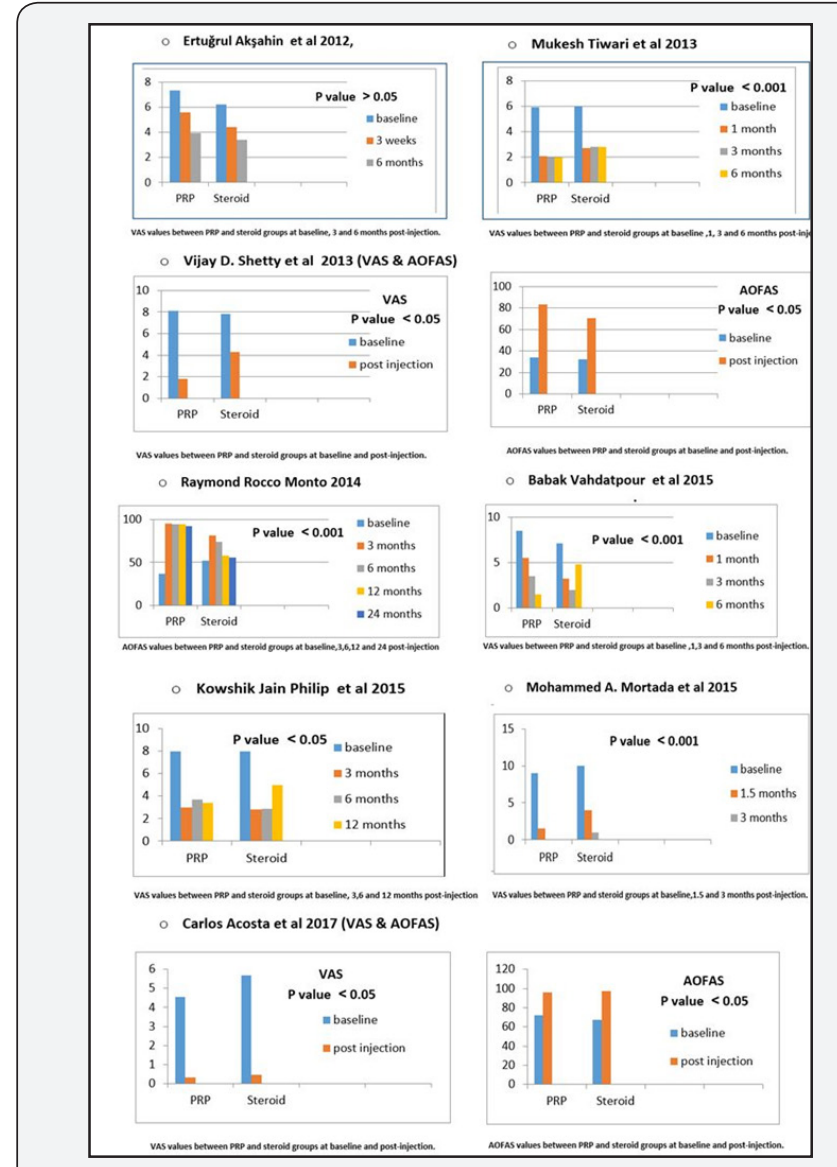

Figure 5 : Improvement that judged by VAS and AOFAS (American orthopedic foot and ankle society scale) in each of included researches. 


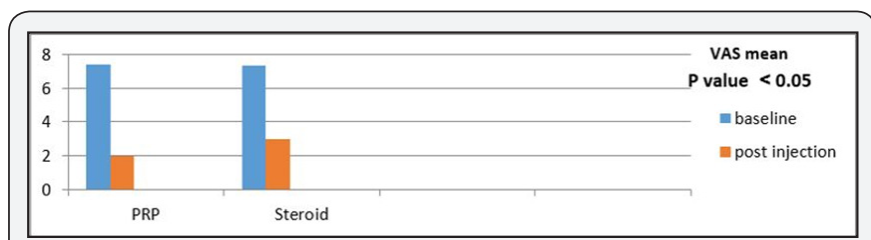

Figure 6 : Chart showing the difference between mean VAS results at baseline and at end of follow-up.

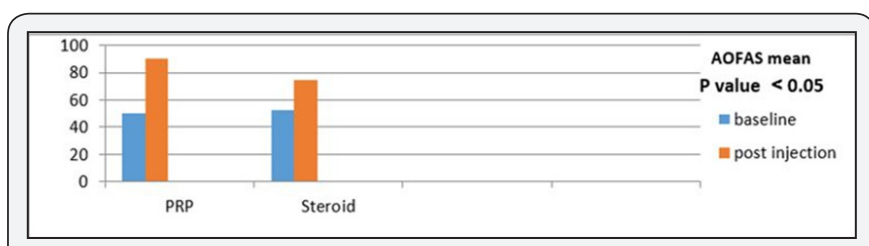

Figure 7 : Chart showing the difference between mean AOFAS results at baseline and at end of follow-up.

\section{Discussion}

Although the most common cause of heel pain is plantar fasciitis, the etiology and treatment are still not fully understood [1]. The diagnosis of plantar fasciitis is based on the patient's history and physical findings for at least 6 months [1]. There is a debate in the literature that will probably modify the treatment modalities is the research concerning the pathophysiology of plantar fasciitis. it is widely believed that plantar fasciitis results from repeated micro-trauma due to overuse, which results in micro-tears of the tissue substance until a macro injury occurs [15].

The early improvement with PRP is most probably mediated by the excessive amount of growth factors and cytokines that creates an inflammatory response that subsequently restarts the cycle of tendon repair interrupting the stagnant healing environment [16]. While with steroid injections it only serves as an anti-inflammatory agent that ceases the inflammation early within days and has a negligible effect on regeneration, remodeling and maturation phase. This occurs at a much slower rate compared with the PRP rich in growth factors [17]. Akşahin et al. showed that there is no significant difference between the steroid and PRP groups in the visual analog scale scores measured at 3 weeks and 6 months $(p>0.05)$. No complications attributable to PRP and corticosteroid injections were observed [11].

Mukesh Tiwari et al. [18] revealed that there was no significant difference in VAS score in both groups of the patients before the treatment. After one month of treatment VAS score significantly fell in both the groups ( $<<0.001)$, but fall in VAS score was higher in PRP therapy. At the completion of 3rd month of treatment VAS score increased in steroid therapy, however it was insignificant and remained constant till six months of treatment. Those who were at PRP therapy VAS score fell at three months and remained constant till six months. At one, three and six months those who are on PRP therapy VAS score remained significantly lower from their counter parts [18].
Raymond Rocco Monto et al. published the results of 40 patients, randomized to receive PRP and Steroid for chronic plantar fasciitis. All patients received ultrasound guided PRP and Steroid injection. The outcome measure in all patients was AOFAS. The Steroid group showed initial improvement, which tapered after 6 months. In the PRP group the benefit remained for 24 months. The limitation of this study is that only AOFAS score was used as the outcome measure. AOFAS may not be the best outcome measure to use in plantar fasciitis, as there was no limitation of function in this pathology and pain specific outcome measures such as RM and VAS are much better for this disorder [8].

Babak Vahdatpour et al. [19] reported that plantar fascia thickness, echogenicity, and positive biconvexity were all improved within follow-up time in both groups receiving PRP and corticosteroid groups, no difference was found across the two groups. In total, it seems that along with clinical scoring systems, using these ultrasonography parameters could be helpful to assess improvement of pain and disability in patients who treated with treatment regiments such as PRP in patients with plantar fasciitis [19].

Kowshik Jain Philip et al. reported both early and long-term outcomes using a range of validated outcome measures. Also, the study reported that improvement following PRP injection occurred within the first 3 months following the injection, but unlike steroid injection, its efficacy did not wear off with time and was maintained for at least 1 year. Also, the study mentioned that injection to be a safe procedure with no reported complication in our patients on review. Whilst they did not use ultrasound guidance for any of the injections, they accepted that this may arguably allow for more accurate placement of the injection, and could be considered [10].

Mohammed A Mortada et al. showed that both groups showed significant clinical and sonographic improvement at the end of the 3 months follow-up period without any complications. More improvement, both clinical and sonographic, was observed in the PRP than in the steroid group at 1.5 months post injection. The early improvement with PRP was most probably mediated by the excessive amount of growth factors and cytokines that creates an inflammatory response that subsequently restarts the cycle of tendon repair interrupting the stagnant healing environment [16]. Carlos Acosta et al. [20] declared that at the end of their study; no significant differences were observed between the two groups. One of the key components for the treatment of the chronic plantar fasciitis involves fascia and gastroc-soleus complex stretching exercises [20].

Both methods were effective and successful in treating plantar fasciitis. Although there is no complication related to steroids are observed, when the potential risks of corticosteroid such as fat pad atrophy, osteomyelitis of the calcaneus, and iatrogenic rupture of the plantar fascia are taken into consideration, PRP injection seems to be safer while being just 
as effective in the treatment of plantar fasciitis [11]. Taking the possible regenerative effect of PRP into consideration, the results of the PRP injection group were expected to be more satisfactory in cases of plantar fasciitis, since it is believed to be a degenerative process rather than an inflammatory reaction [15].

\section{Conclusion}

The PRP local injection is a new, readily available and well tolerated, with prolonged effect and safe choice of therapy for chronic pf and is not inferior to steroid injection in a short term up. Comparing the long-term efficacy, both clinically and sonographically is necessary to confirm their sustained effect. We can conclude that the use of PRP is an effective treatment method for patients with plantar fasciitis which do not respond to conservative treatment. However, the cost and the time for preparation the PRP are two of the disadvantages of this treatment. Steroid therapy effect appears in a short period (about 3 months post-injection), but PRP has a prolonged effect (for about 12 months post-injection). The PRP injection is better than steroid injection in relieving the pain of planar fasciitis and in improvement of the function of the patient foot.

\section{References}

1. Beeson P (2014) plantar fasciopathy: revisiting the risk factors. Foot Ankle Surg 20(3): 160-165

2. Goff Jd, Crawford R (2011) Diagnosis and treatment of plantar fasciitis. Am Fam physician 84(6): 676-682.

3. Rosenbaum Aj, Dipreta Ja, Misener D (2014) plantar heel pain, Med Clin North Am 98(2): 339-352.

4. Lareau Cr, Sawyer Ga, Wang Jh, Digiovannicw (2014) plantar and medial heel pain: diagnosis and management. J Am Acad Orthop Surg 22(6): 372-380.

5. Cutts S, Obi N, Pasapula C, Chan W (2012) plantar fasciitis. Ann R Coll Surg Engl 94(8): 539-542.

6. Tahririan Ma, Motififard M, Tahmasebi Mn, SiaVAShi B (2012) plantar fasciitis. J Res med sci 17 (8): 799-804.

7. Jeswani T, Morlese J, Mcnally Eg (2009) getting to the heel of the problem: plantar fascia lesions, Clinradiol 64(9): 931-939.
8. Monto RR (2013) platelet-rich plasma and plantar fasciitis, sports med arthrosc 21(4): 220-224.

9. Tu P, Bytomskijr (2011) Diagnosis of heel pain. Am Fam Physician 84(8): 909-916.

10. Jain K, Murphy Pn, Clough Tm (2015) platelet rich plasma versus corticosteroid injection for plantar fasciitis: a comparative study. Foot (Edinb) 25(4): 235-237.

11. Say F, Gürlërd, Inkaya E, Bülbül M (2014) comparison of platelet-rich plasma and steroid injection in the treatment of plantar fasciitis. Acta Orthop Traumatol Turc 48(6): 667-672.

12. Sampson S, Gerhardt M, Mandelbaum B (2008) Platelet-rich plasma injection grafts for musculoskeletal injuries. Curr Rev Musculoskelet Med 1(3-4): 165-174.

13. Redmond AC, Landorf KB, Keenan AM (2009) Contoured, prefabricated foot orthoses demonstrate comparable mechanical properties to contoured, customized foot orthoses: a plantar pressure study. J Foot Ankle Res 2: 20 .

14. Chan YH (2003) Biostatistics 102: quantitative data--parametric \& non-parametric tests. Singapore Med J 44(8): 391-396.

15.L Zhiyun, J Tao, S Zengwu (2013) Meta-analysis of high-energy extracorporeal shock wave therapy in recalcitrant plantar fasciitis. Swiss Med wkly 143: w13825.

16. Taylor DW, Petrera M, Hendry M, Theodoropoulos JS (2011) A systematic review of the use of platelet-rich plasma in sports medicine as a new treatment for tendon and ligament injuries. Clin J Sport Med 21(4): 344-352.

17. Nepple JJ, Matava MJ (2009) Soft tissue injections in the athlete. Sports Health 1(5): 396-404.

18. Tiwari M, Bhargava R (2013) Platelet rich plasma therapy: A comparative effective therapy with promising results in plantar fasciitis, J Clin Orthop Trauma 4(1): 31-35.

19. Vahdatpour, Babak (2016) Beneficial effects of platelet-rich plasma on improvement of pain severity and physical disability in patients with plantar fasciitis: a randomized trial, advanced biomedical research 5: 179.

20. Acosta-Olivo C, Elizondo-Rodriguez J, Lopez-Cavazos R, VilchezCavazos F, Simental-Mendia M, et al. (2017) Plantar Fasciitis a Comparison of Treatment with Intralesional Steroids versus PlateletRich Plasma A Randomized, Blinded Study. J Am Podiatr Med Assoc 107(6): 490-496.

\section{Your next submission with Juniper Publishers will reach you the below assets}

